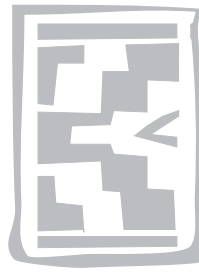

\title{
Description and comparison of the pupae of a further two Culicoides (Avaritia) species from the dung of large herbivores in South Africa (Diptera: Ceratopogonidae)
}

\author{
HILDA NEVILL ${ }^{1 *}$, E.M. NEVILL ${ }^{1}$ and G.J. VENTER ${ }^{2}$
}

\begin{abstract}
NEVILL, HILDA, NEVILL, E.M. \& VENTER, G.J. 2009. Description and comparison of the pupae of a further two Culicoides (Avaritia) species from the dung of large herbivores in South Africa (Diptera: Ceratopogonidae). Onderstepoort Journal of Veterinary Research, 76:277-284

In 2007 Nevill, Venter, Meiswinkel \& Nevill demonstrated that the pupae of five Culicoides species belonging to the Imicola complex of the subgenus Avaritia could readily be differentiated from one another using various morphological characters. Three of the described species, Culicoides bolitinos Meiswinkel 1989; Culicoides loxodontis Meiswinkel 1992 and Culicoides sp. \# 107 (= C. kwagga, Meiswinkel, unpublished thesis 1995), were reared from the dung of large herbivores, which included buffaloes, elephants, white and black rhinoceroses and zebras. However, during that study a further two Avaritia species, neither of which belonged to the Imicola complex, were reared from dung and these are the subject of the present study.

For the past 20 years the adults of these two new closely related species have been known as Culicoides sp. \# 54 pale form (p.f.) Meiswinkel and Culicoides sp. \# 54 dark form (d.f.) Meiswinkel. The taxonomic description and formal naming of the adults of these two species has yet to be done. The present description and comparison of their pupae show that they are two clearly distinct species; that there is no group of morphological characters that can be used to differentiate these two species from the previously described five species of the Imicola complex; and finally that there was no difference between the pupae of $C$. sp. \# 54 d.f. nor $C$. sp. \# 54 p.f. reared from the dung of different host animals.

Keywords: Culicoides, Diptera, dung, pupae, morphology, South Africa
\end{abstract}

\section{INTRODUCTION}

In 1974 Dyce \& Marshall (1989) "explored the likelihood of Culicoides species developing in the dung of native game animals." They succeeded in rearing the adults of four Culicoides species from the dung of African elephants (Loxodonta africana), African buffaloes (Syncerus caffer) and Burchell's zebras (Equus burchelli). That study motivated Meiswinkel

* Author to whom correspondence is to be directed. E-mail: nevill@slingshot.co.nz

15 Eastside Drive, Pukekohe, 2120 New Zealand

2 Parasites, Vectors \& Vector-borne Diseases, ARC-Onderstepoort Veterinary Institute, Private Bag X5, Onderstepoort, 0110 South Africa

Accepted for publication 19 February 2009-Editor of the ARC-Onderstepoort Veterinary Institute (ARC$\mathrm{OVI})$ to further investigate the dung-inhabiting Culicoides fauna of the large herbivores of the Kruger National Park, South Africa. This resulted in his rearing six species of the subgenus Avaritia from elephant dung (Meiswinkel \& Braack 1994; Meiswinkel 1995). These were Culicoides kanagai Khamala \& Kettle 1971; Culicoides loxodontis, Culicoides tororoensis Khamala \& Kettle 1971; Culicoides. sp. \# 50, Culicoides sp. \# 54 pale form (p.f.) Meiswinkel and Culicoides sp. \# 54 dark form (d.f.) Meiswinkel. In addition, Culicoides bolitinos was reared from buffalo dung (Meiswinkel 1989) and Culicoides sp. \# 107 (= C. kwagga, Meiswinkel, unpublished thesis 1995) from the dung of zebra and white rhinoceros (Ceratotherium simum) (Meiswinkel 1995; Meiswinkel, Venter \& Nevill 2004). 
By 1995 Meiswinkel had recognized 112 South African Culicoides species; 43 of these were new to science which he tentatively numbered until they can be described formally (Meiswinkel et al. 2004). Two of these undescribed species were the very closely related Avaritia species which he provisionally named C. sp. \# 54 p.f. and C. sp. \# 54 d.f. (Meiswinkel \& Braack 1994). Although their wing patterns are nearly impossible to differentiate under a dissecting microscope, $C$. sp. \# 54 d.f. is generally the smaller of the two and has a darker wing pattern.

Since about 1983 when C. sp. \# 54 d.f. and C. sp. \# 54 p.f. were first recognized they have been referred to in various publications (Meiswinkel \& Braack 1994; Meiswinkel 1995, Meiswinkel et al. 2004). The most detailed reference to C. sp. \# 54 (s.l.) is that of Meiswinkel \& Braack (1994) on five Culicoides species collected live from behind the ears of African elephants in the Kruger National Park. They stated that the two species differed in their biology with $C$. sp. \# 54 p.f. appearing to be exclusively associated with elephants, from whose dung it had been reared in large numbers. The dark form on the other hand had been reared from a variety of dung types including elephants, zebras and white and black rhinoceroses (Diceros bicornis). A further difference noted by Meiswinkel (1995) was that, when rearing Culicoides species from elephant dung, C. sp. \# 54 p.f. was the first to emerge, followed by C. sp. \# 54 d.f. and then $C$. loxodontis.

Between 1989 and 1993 the senior author studied, described and compared the pupae of the known dung-breeding Culicoides (Avaritia) species. From collections of dung made at many localities she was able to recover the pupae of five species, namely $C$. bolitinos, C. loxodontis, C. sp. \# 107 (= C. kwagga), C. sp. \# 54 p.f. and C. sp. \# 54 d.f. Unfortunately no pupae of the remaining dung-inhabiting species $C$. kanagai and C. sp. \# 50 could be found in the dung collections. The pupae of the first three of the above mentioned Avaritia species were described in a comparative study of the pupae of five species of the C. imicola complex (Nevill, Venter, Meiswinkel \& Nevill 2007).

This paper describes the pupae of the remaining two dung-breeding Culicoides species, C. sp. \# 54 p.f. and C. sp. \# 54 d.f. and compares them with those already described. Although the taxonomic description and formal naming of the adults of these two species have yet to be done, the present description and comparison of their pupae will contribute to recognizing them as two clearly distinct spe- cies. It will also assist with the differential diagnosis of the dung-breeding Culicoides species of this region.

\section{MATERIALS AND METHODS}

The collection method, recovery of pupae and linkrearing of adults have been described in detail by Nevill et al. (2007). Some of the dung collected during the period April 1990 to September 1992 towards the 2007 study also yielded $C$. sp. \# 54 d.f. and C. sp. \# 54 p.f.

Eighty slide-mounted pupae of $C$. sp. \# 54 d.f. were studied. These were bred out of dung collected from the Kruger National Park (KNP) (elephant, white rhinoceros, black rhinoceros); the Hluhluwe Game Reserve in KwaZulu-Natal Province (elephant and white rhinoceros); the iMfolozi Game Reserve, also in KwaZulu-Natal (white rhinoceros and zebra) and the Van Riebeeck Nature Reserve near Pretoria (zebra). Forty-four slide-mounted pupae of $C$. sp. \# 54 p.f. were studied, all of which were bred from elephant dung collected in the KNP.

Slide preparation, character terminology, abbreviations and illustrations follow Nevill et al. (2007) and Nevill \& Dyce (1994). The identification of the linkreared specimens was confirmed by $R$. Meiswinkel of the ARC-OVI.

\section{RESULTS}

\section{Pupae Culicoides sp. \# 54 dark form \\ (Meiswinkel) (Fig. 1A-H; Tables 1-2)}

\section{Description}

Mean total length $1.52 \mathrm{~mm}(1.44-1.64 \mathrm{~mm} ; n=10)$. Cephalothorax slightly darker yellow than abdomen.

\section{RESPIRATORY ORGAN (Fig. 1A; Table 1)}

Proximal one third darker yellow than distal two thirds. Horn short, proximal third wider than distal two thirds. Folds medially. Scales absent. Lateral spiracles five (4-6), medially situated spiracles on unpigmented prominences. Terminal spiracles three (2-4), the most distal lateral spiracle sometimes indistinguishable from terminal spiracles. Pedicel short, 0.17 length of horn.

\section{Operculum (FIG. 1B; TABLE 1)}

Yellow. In both females and males, opercular disc wider than long; distance between am tubercles dis- 

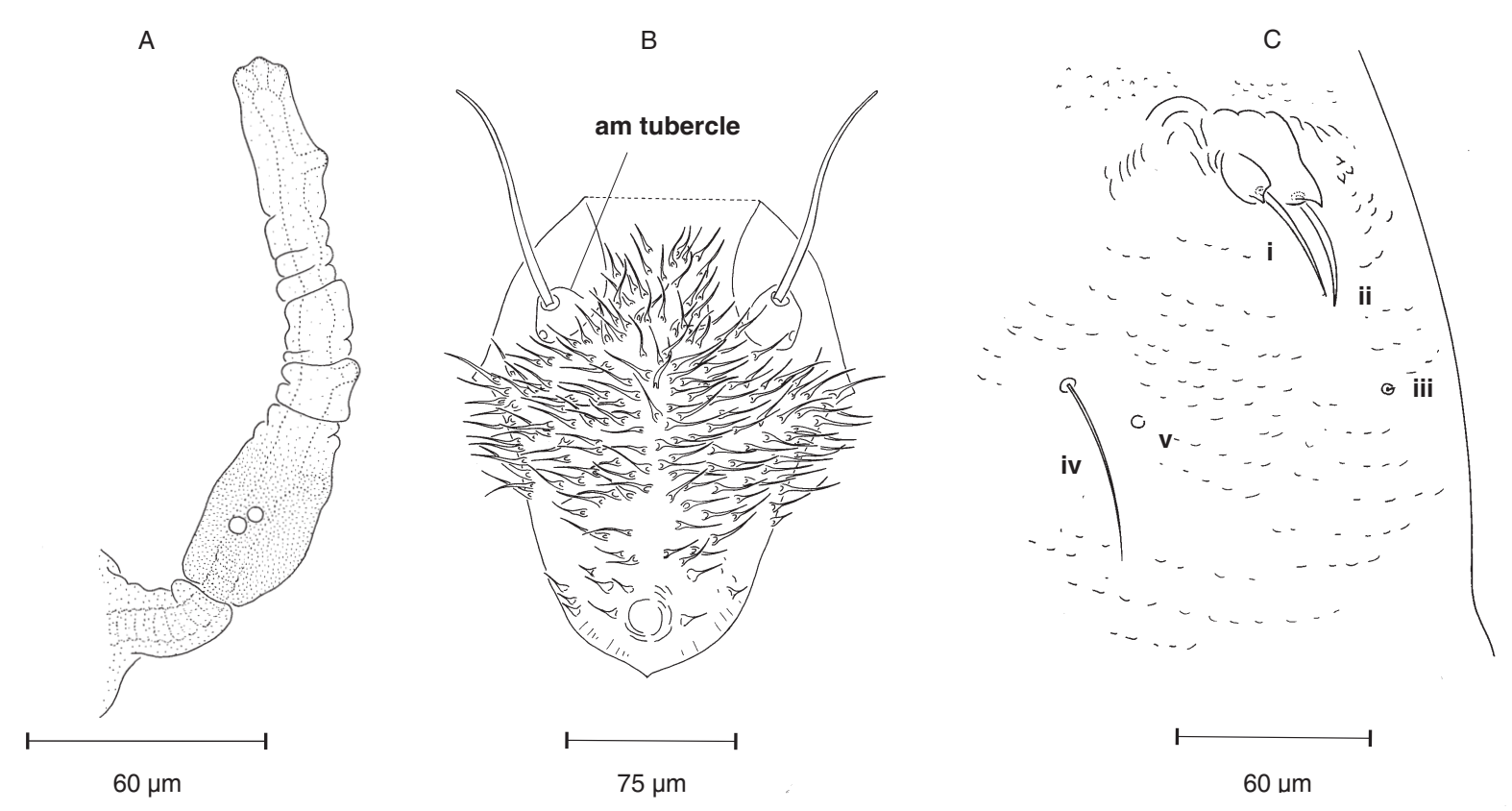

D
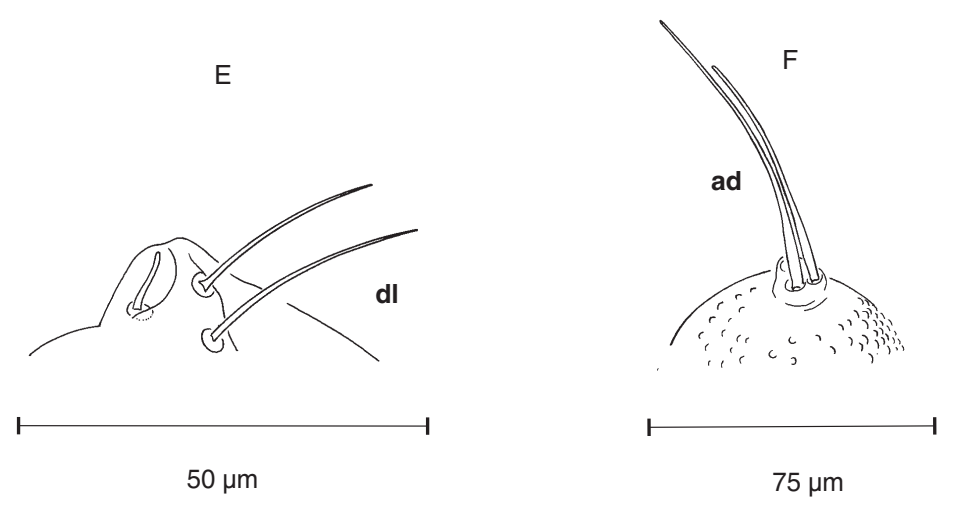

G
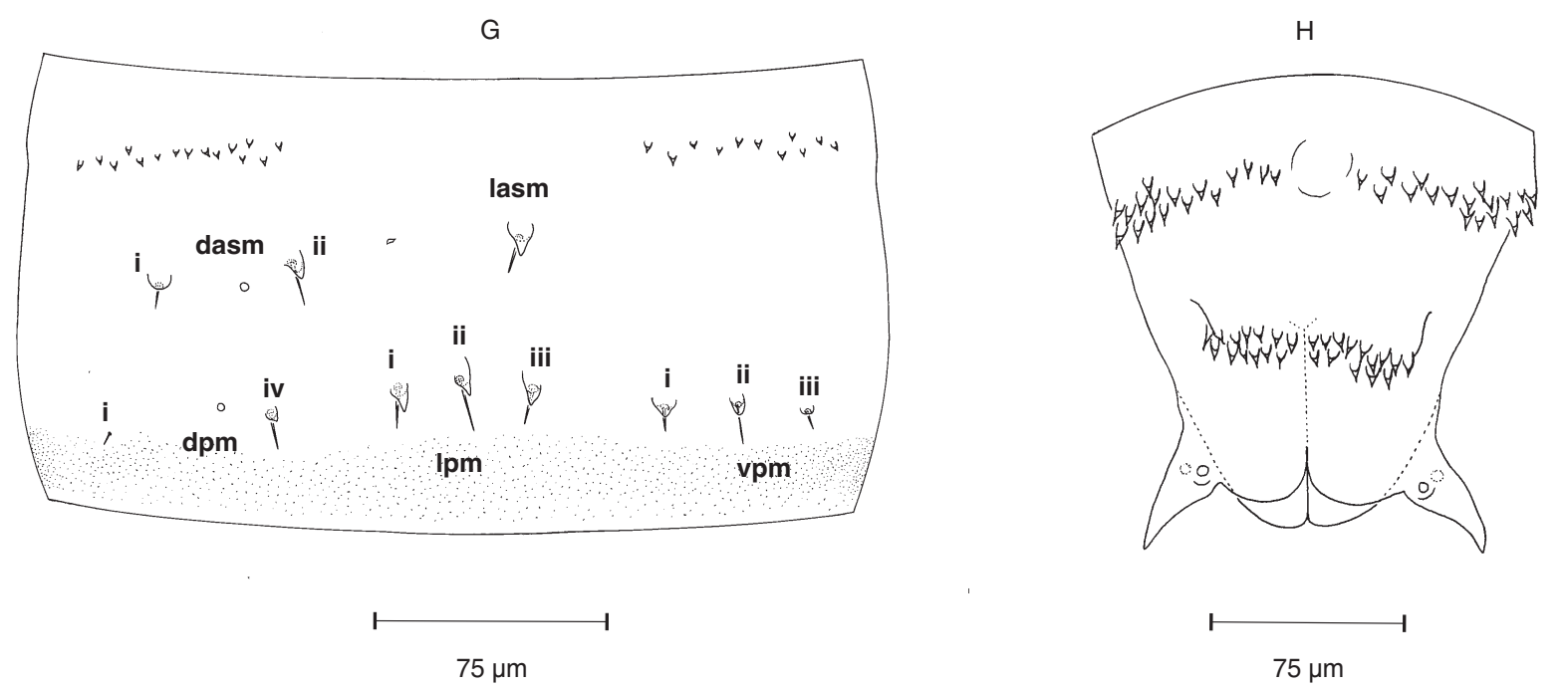

FIG. 1 The pupa of Culicoides sp. \# 54 dark form: (A) prothoracic respiratory organ; (B) $q$ operculum; $(C)$ thorax (setae $d i-d ~ v)$; (D) ventrolateral setae (vl); (E) dorsolateral tubercle (dl); (F) anterodorsal tubercle (ad); (G) fourth abdominal segment; (H) caudal segment 
Pupae of two Culicoides (Avaritia) species from dung of herbivores in South Africa

tinctly greater in females than males. Long setaceous spines on anterior half of disc and between am tubercles; sparser and shorter on posterior half of disc. Nodules and spinules absent; large protuberance posteromedially.

HEAD TUBERCLES AND SETAE (Fig. 1B, D and F; Table 1)

Am tubercle without spurs; seta very long, stout; basal sensillum (Fig. 1B). Vm sensilla and setae absent. Two thin vl setae of almost equal length and width; a third sensillum present (Fig. 1D). Ad tubercle without spurs; seta i very long, stout; seta ii long, slightly thinner; a third sensillum present (Fig. 1F).

ThORAX (Fig. 1C and E; Tables 1-2)

Dorsal tubercles small; $d$ i and d ii closely approximated, each with a large, sharp spur and a moderate length and width, sharp seta; $d$ iii seta minute; $d$ iv seta short, thin, mostly not elevated; $d$ v sensillum. Small pits around and between dorsal tubercles (Fig. 1C). DI tubercle with three setae: one terminal, short, thin, sharp; one lateral, short, thin, sharp and one basal, in fold, of equal width throughout (Fig. 1E).

\section{ABdomen (Fig. 1G; Tables 1-2)}

All tubercles very small. Dpm i seta on slight prominence, minute; dpm ii, iii and v absent; dpm iv base rounded, with or without sharp spur, seta short, thin, sharp. Sensillum present between dpm i and iv. Lpm i-iii with more elongated bases, each with a large, sharp, spur; Ipm i and iii seta short, thin, sharp; Ipm ii seta longer, thinner than Ipm i and iii. Vpm i-iii bases rounded, each with or without a sharp spur; vpm i seta short, thin, sharp; vpm ii seta longer, thinner than vpm i; vpm iii seta shorter, thinner than vpm i, sharp. Dasm i without spur, seta short, thin, sharp; dasm ii base rounded, mostly with a sharp spur, seta longer, thinner than i; sensillum present between dasm i and ii. Lasm base elongated, seta short, thin, sharp. Anterolateral spiracle present. Anterior band of spinules interrupted dorsally, ventrally and laterally. Posterior margin of segment granulate.

\section{CAudAL SEGMENT (Fig. 1H; Table 1)}

Anterior band of spines interrupted dorsally. Dorsomedian row of 15-37 spines, interrupted medially. Posterolateral processes short; two sensilla present; spinules absent, tips rather sharp; sometimes slightly pigmented.
Material examined

MPUMALANGa PROVINCE

27 우 $9 \mathrm{O}^{\wedge} \mathrm{O}^{\lambda}$, west of Skukuza Rest Camp, (24⒌ S; $31^{\circ} 35^{\prime}$ E) Kruger National Park (KNP), 1991. viii.27, H. Nevill, G. Venter, R. Meiswinkel, M. Smit, ex elephant dung.

1 오 $10 \partial^{\lambda}$, west of Skukuza Rest Camp, (24⒌ $59^{\prime}$ S; 313ํㄹ E), KNP, 1991.ix.19, H. Nevill, K. Newberry, K. Kappmeier Green, ex white rhinoceros dung.

$2+q 3 \hat{\partial} \widehat{A}$, north-west of Lower Sabie Rest Camp,

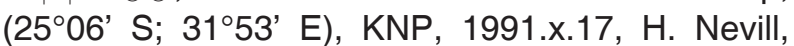
E.M. Nevill, G. Venter, R. Meiswinkel, ex black rhinoceros dung.

\section{Gauteng Province}

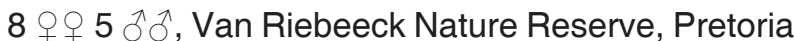
(2552' S; 28¹6’ E), 1990.iv.05, H. Nevill, E.M. Nevill, M. Edwardes, ex zebra dung.

\section{KWAZULU-Natal PRovince}

3 우우 1 스, iMfolozi Game Reserve (2850' S; 31 ${ }^{\circ} 35^{\prime}$ E), 1990.ix.20, H. Nevill, E.M. Nevill, ex white rhinoceros dung.

1 ㅇ, iMfolozi Game Reserve, (2850' S; $\left.31^{\circ} 35^{\prime} \mathrm{E}\right)$, 1990.ix.20, H. Nevill, E.M. Nevill, ex zebra dung.

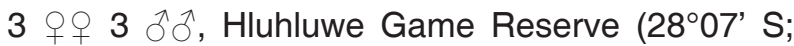
$32^{\circ} 05^{\prime}$ E), 1992.ix.10, H. Nevill, E.M. Nevill, K. Kappmeier Green, ex elephant dung.

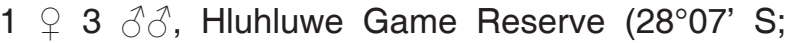
$32^{\circ} 05^{\prime}$ E), 1992.ix.10, H. Nevill, E.M. Nevill, K. Kappmeier Green, ex white rhinoceros dung.

\section{Pupae Culicoides sp. \# 54 pale form \\ (Meiswinkel) (Fig. 2A-H; Tables 1-2)}

\section{Description}

Mean total length $1.43 \mathrm{~mm}(1.36-1.50 \mathrm{~mm} ; n=7)$. Yellow-brown, cephalothorax slightly darker than abdomen. Two conspicuous protuberances on operculum.

\section{RESPIRATORY ORGAN (Fig. 2A; Table 1)}

Distal two thirds pale, proximal third darker. Horn short, proximal one third wider than distal two thirds. Folds medially. Scales absent. Lateral spiracles five (4-7), medial spiracles on small, slightly pigmented prominences. Terminal spiracles three (2-4), the most distal lateral spiracles sometimes indistin- 
A

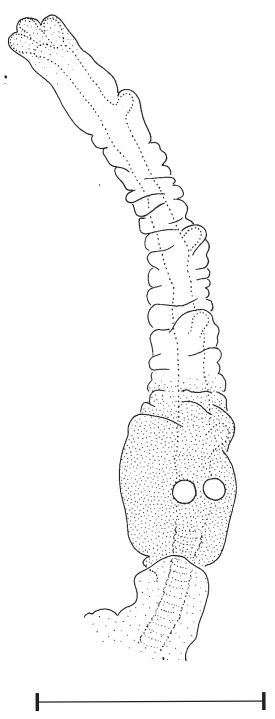

$60 \mu \mathrm{m}$

D
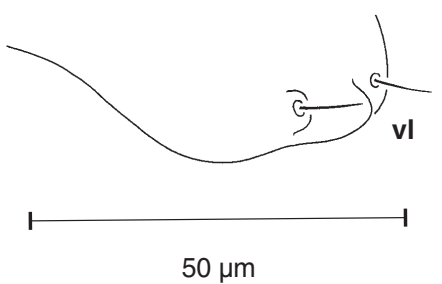

B
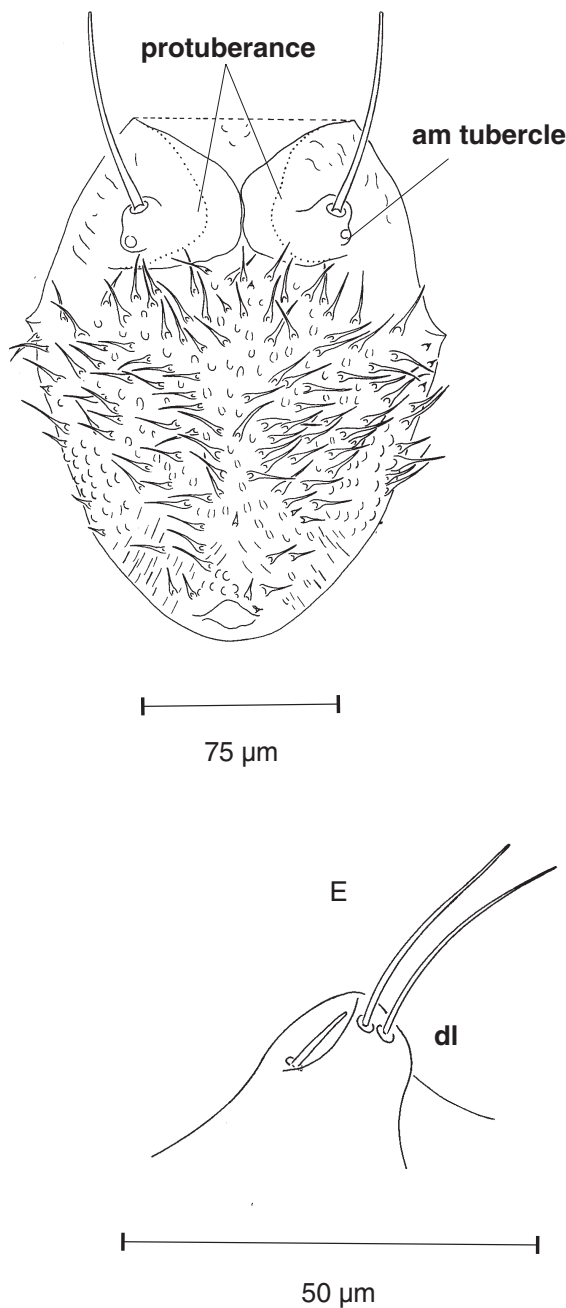

C
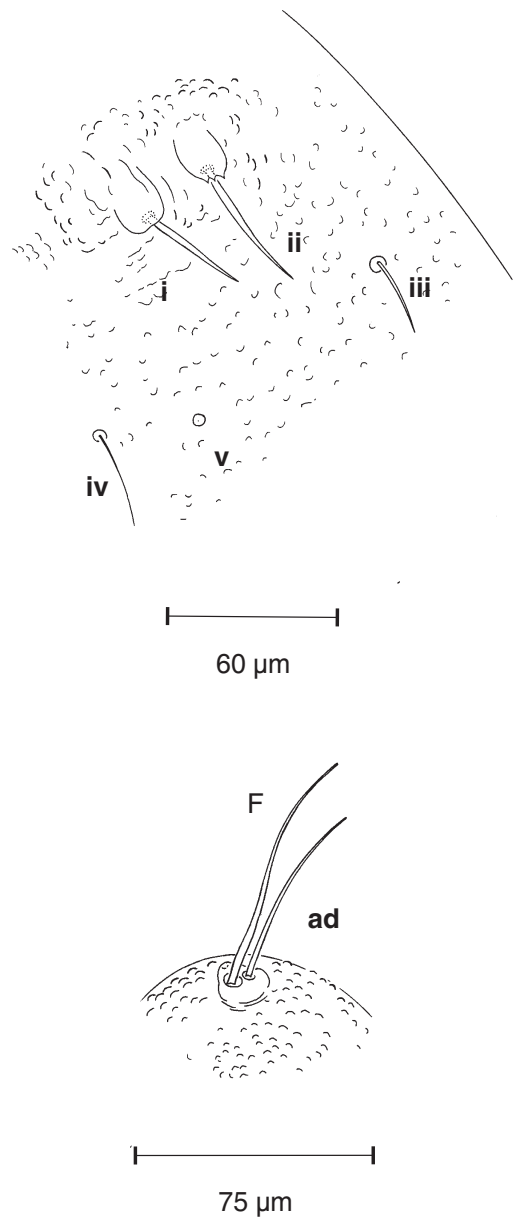

G

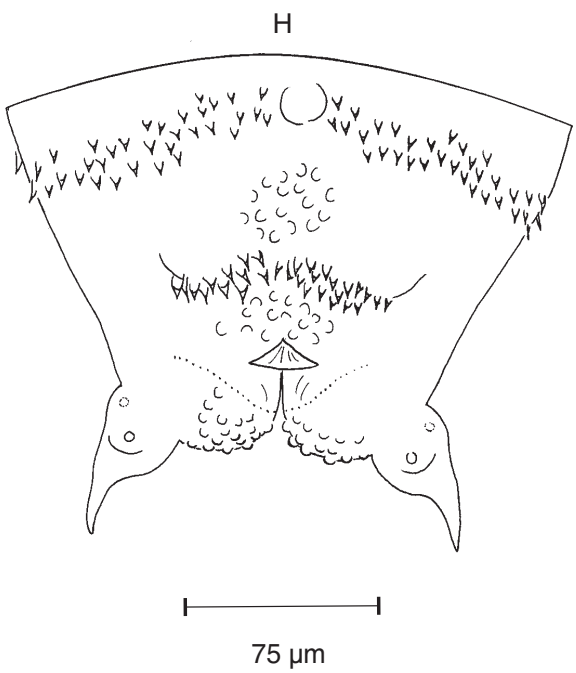

$75 \mu \mathrm{m}$

$75 \mu \mathrm{m}$

FIG. 2 The pupa of Culicoides sp. \# 54 pale form: (A) prothoracic respiratory organ; (B) $q$ operculum; (C) thorax (setae d i - d v); (D) ventrolateral setae (vl); (E) dorsolateral tubercle (dl); (F) anterodorsal tubercle (ad); (G) fourth abdominal segment; $(\mathrm{H})$ caudal segment 
Pupae of two Culicoides (Avaritia) species from dung of herbivores in South Africa

guishable from terminal spiracles. Pedicel short 0.15 length of horn.

\section{OPERCULUM (Fig. 2B; Table 1)}

Yellow-brown. In both $\phi+9$ and $\widehat{\partial} \delta$ operculum wider than long. Long setaceous spines on anterior half of disc, spines sparser and shorter posteriorly. Disc and posteromedial protuberance heavily noduled.

HEAD TUBERCles AND SETAE (Fig. 2B, D and F; Table 1)

Am tubercle on large, distinct protuberance (Fig. 1B), am tubercle without spur, seta long, stout; basal sensillum present (Fig. 1B). Vm setae absent. Two thin vl setae of almost equal length and width; a third sensillum on slight prominence (Fig. 1D). Ad tubercle without spurs, seta i long, stout; seta ii shorter, thinner; a third sensillum, elevated (Fig. 1F).

\section{THORAX (Fig. 2C and E; Tables 1-2)}

Dorsal tubercles small; $d$ i and d ii not too closely approximated. Both tubercles with 1-4 small, sharp spurs, seta i of moderate length and width, sharp; seta ii slightly longer, stouter, sharp; d iii tubercle small, seta short, moderate width, sharp; $d$ iv short, thin; $d v$ sensillum on slight prominence. Small pits between tubercles (Fig. 2C). DI tubercles with three setae: one terminal, short, thin; one lateral, slightly longer; one basal, in fold, of equal width throughout (Fig. 2E).

\section{ABDOMEN (Fig. 2G; Tables 1-2)}

Tubercles of moderate size, covered with spines and spinules. Dpm ii, iii and v absent. Dpm i base rounded, seta minute; dpm iv base rounded, seta short, thin, sharp, sensillum present between dpm i and dpm iv. Lpm i-iii bases more elongated, Ipm i seta short, thin, sharp; Ipm ii seta longer than i, thinner; Ipm iii longer than $i$ and ii, stouter, sharp. Vpm seta i short, thin, sharp; vpm ii seta longer, thinner than i and iii; vpm iii seta shorter than i. Dasm i seta short, thin, sharp; dasm ii seta longer than i, thinner; sensillum present between dasm $\mathrm{i}$ and dasm ii. Lasm base elongated, seta slightly longer than Ipm iii, equal width. Anterolateral spiracle present. Anterior band of spinules interrupted dorsally, ventrally and laterally. Large nodules cover whole integument.

\section{CAUDAL SEGMENT (Fig. 2H; Table 1)}

Anterior band of spines interrupted dorsally. Dorsomedian row of 21-40 spines interrupted medially.
Posterolateral processes of moderate length; two sensilla present; spinules absent, tips rather sharp, sometimes slightly pigmented. Large nodules present antero- and posteromedially on segment dorsally.

\section{Material examined}

\section{MPUMALANGa PROVINCE}

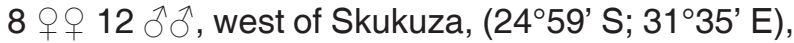
Kruger National Park (KNP), 1991.v.14, H. Nevill, H. Heyne, ex elephant dung.

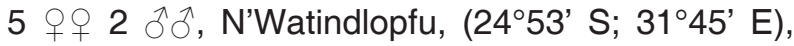
KNP, 1991.ix.24, H. Nevill, G. Venter, R. Meiswinkel, M. Smit, ex elephant dung.

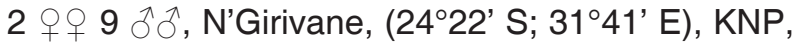
1992.vii.22, H. Nevill, R. Meiswinkel, ex elephant dung.

\section{LIMPOPO PROVINCE}

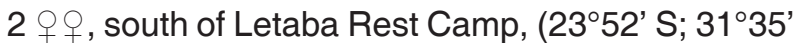
E), KNP, 1992.i.29, H. Nevill, R. Meiswinkel, ex elephant dung.

\section{Additional material examined}

MPUMALANGA PROVINCE. 2 우 $2 \hat{\mathrm{o}} \hat{\mathrm{d}}$, west of

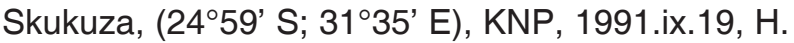
Nevill, K. Newberry, ex white rhinoceros dung.

\section{DISCUSSION AND CONCLUSION}

\section{Differential diagnosis}

The most important morphological characters which differentiate C. sp. \# 54 d.f. from C. sp. \# 54 p.f. are:

- the two large protuberances on the operculum of C. sp. \# 54 p.f. that can be observed under $25 x$ magnification;

- length differences between setae of Ipm i-iii; Ipm ii always longest in C. sp. \# 54 d.f. and Ipm iii always longest in $C$. sp. \# 54 p.f.;

- length differences between setae of d iii, with those of C. sp. \# 54 p.f. distinctly longer;

- the abdominal tubercles, that of $C$. sp. \# 54 p.f. covered with a number of spines and that of $C$. sp. \# 54 d.f. with only a large, sharp spur;

- the integument of $C$. sp. \# 54 p.f. is covered with nodules, that of $C$. sp. \# 54 d.f. clear.

The pupae of the above-mentioned two species, as well as the five Imicola complex species, C. bolitinos, 
TABLE 1 Measurements $(\mu \mathrm{m})$, ratios and counts of the morphological characters of the respiratory organ, operculum and caudal segment of the pupae of Culicoides sp. \# 54 dark form and Culicoides sp. \# 54 pale form

\begin{tabular}{|c|c|c|c|c|c|c|}
\hline \multirow{2}{*}{ Species } & \multicolumn{3}{|c|}{ C. sp. \# 54 d.f. } & \multicolumn{3}{|c|}{ C. sp. \# 54 p.f. } \\
\hline & Range & Mean & $n$ & Range & Mean & $n$ \\
\hline \multicolumn{7}{|l|}{ Respiratory organ (Fig. 1A and 2A) } \\
\hline $\begin{array}{l}\text { Length horn }(\mathrm{H}) \\
\text { Length pedicel }(\mathrm{P}) \\
\mathrm{P} / \mathrm{H} \text { ratio } \\
\text { Lateral spiracles } \\
\text { Terminal spiracles }\end{array}$ & $\begin{array}{l}111.5-184.5 \\
19.0-35.0 \\
0.10-0.22 \\
4-7 \\
2-6\end{array}$ & $\begin{array}{l}142.9 \\
24.9 \\
0.17 \\
\text { Highest freq. } 6 \\
\text { Highest freq. } 4\end{array}$ & $\begin{array}{l}99 \\
115 \\
97 \\
111 \\
102\end{array}$ & $\begin{array}{l}119.0-173.0 \\
16.0-34.0 \\
0.12-0.21 \\
4-7 \\
2-4\end{array}$ & $\begin{array}{l}150.7 \\
22.6 \\
0.15 \\
\text { Highest freq. } 5 \\
\text { Highest freq. } 3\end{array}$ & $\begin{array}{l}51 \\
47 \\
43 \\
49 \\
48\end{array}$ \\
\hline \multicolumn{7}{|l|}{ Operculum (Fig. 1B and 2B) } \\
\hline $\begin{array}{l}\text { Length }(\mathrm{OL})+ \\
\hat{\sigma} \\
\text { Width }(\mathrm{OW}) \stackrel{+}{ } \\
\hat{\sigma} \\
\text { Ratio }(\mathrm{OW} / \mathrm{OL})+ \\
\delta \\
\text { Spine length }\end{array}$ & $\begin{array}{l}123.5-167.5 \\
136.0-170.5 \\
149.0-188.5 \\
155.0-185.0 \\
1.10-1.36 \\
1.00-1.22 \\
23.0-41.5\end{array}$ & $\begin{array}{l}139.2 \\
146.5 \\
170.3 \\
170.3 \\
1.22 \\
1.14 \\
30.0\end{array}$ & $\begin{array}{l}41 \\
33 \\
42 \\
32 \\
41 \\
32 \\
63\end{array}$ & $\begin{array}{l}125.5-155.5 \\
131.0-175.0 \\
156.0-215.5 \\
176.0-224.0 \\
1.21-1.43 \\
1.21-1.46 \\
15.5-26.0\end{array}$ & $\begin{array}{l}135.4 \\
154.6 \\
181.8 \\
181.7 \\
1.34 \\
1.28 \\
21.1\end{array}$ & $\begin{array}{l}14 \\
18 \\
14 \\
18 \\
15 \\
18 \\
33\end{array}$ \\
\hline \multicolumn{7}{|l|}{ Caudal segment (Fig. 1H and 2H) } \\
\hline $\begin{array}{l}\text { Length posterolateral processes } \\
\text { No. dorsal spines }\end{array}$ & $\begin{array}{l}30.0-45.5 \\
10-30\end{array}$ & $\begin{array}{l}38.6 \\
22.6\end{array}$ & $\begin{array}{l}98 \\
59\end{array}$ & $\begin{array}{l}42.5-65.0 \\
21-44\end{array}$ & $\begin{array}{l}53.6 \\
33.8\end{array}$ & $\begin{array}{l}55 \\
26\end{array}$ \\
\hline
\end{tabular}

TABLE 2 Lengths $(\mu \mathrm{m})$ of selected cephalothoracic and abdominal setae of the pupae of Culicoides sp. \# 54 dark form and Culicoides sp. \# 54 pale form

\begin{tabular}{|c|c|c|c|c|c|c|}
\hline \multirow{2}{*}{ Species } & \multicolumn{3}{|c|}{ C. sp. \# 54 d.f. } & \multicolumn{3}{|c|}{ C. sp. \# 54 p.f. } \\
\hline & Range & Mean & $n$ & Range & Mean & $n$ \\
\hline \multicolumn{7}{|c|}{ Lengths of cephalothoracic setae (Fig. 1B, C and 2B, C) } \\
\hline Am & $84.5-114.0$ & 105.0 & 112 & $69.5-92.5$ & 81.3 & 36 \\
\hline Ad $\mathrm{i}$ & $90.5-129.0$ & 108.3 & 70 & $76.0-100.0$ & 88.7 & 29 \\
\hline Ad ii & $70.5-100.5$ & 85.1 & 72 & $55.5-76.0$ & 65.0 & 28 \\
\hline $\mathrm{Di}$ & $32.5-55.0$ & 41.8 & 58 & $30.0-45.5$ & 38.6 & 27 \\
\hline D ii & $28.5-55.5$ & 42.0 & 57 & $37.5-50.5$ & 43.3 & 26 \\
\hline D iii & Minute & & 58 & $16.0-36.0$ & 22.4 & 21 \\
\hline D iv & $20.0-35.5$ & 25.9 & 55 & $19.0-30.5$ & 25.6 & 24 \\
\hline \multicolumn{7}{|c|}{ Lengths of abdominal setae (Fig. 1G and 2G) } \\
\hline Dpm i & $4.0-7.5$ & 5.2 & 33 & $5.0-7.5$ & 5.9 & 14 \\
\hline Dpm iv & $6.0-15.5$ & 10.5 & 40 & $6.0-11.0$ & 8.3 & 20 \\
\hline Dasm i & $6.5-14.0$ & 9.5 & 40 & $5.5-11.0$ & 8.8 & 24 \\
\hline Dasm ii & $12.5-24.5$ & 15.3 & 42 & $14.0-31.0$ & 19.5 & 28 \\
\hline Lpm i & $9.5-17.5$ & 11.6 & 38 & $6.0-16.5$ & 10.5 & 27 \\
\hline Lpm ii & $12.5-24.0$ & 17.2 & 36 & $16.0-26.0$ & 20.4 & 18 \\
\hline Lpm iii & $9.5-15.5$ & 10.4 & 38 & $20.0-31.0$ & 25.6 & 26 \\
\hline Lasm & $7.0-15.5$ & 10.7 & 35 & $21.0-35.0$ & 28.5 & 29 \\
\hline Vpm i & $8.0-14.5$ & 9.8 & 39 & $5.5-12.0$ & 9.1 & 24 \\
\hline Vpm ii & $10.5-21.0$ & 14.0 & 38 & $15.0-32.5$ & 18.5 & 23 \\
\hline Vpm iii & $6.0-12.5$ & 8.3 & 36 & $5.5-9.0$ & 6.9 & 19 \\
\hline
\end{tabular}


C. imicola, C. loxodontis, Culicoides tuttifrutti Meiswinkel, Cornet \& Dyce 2003 and C. sp. \# 107 (= C. kwagga), described by Nevill et al. (2007), are all easily separated from one another by their morphological and ecological characters. This contributes to the differentiation of closely related species where the adults are difficult to separate. No group of characters could, however, differentiate the Imicola complex from C. sp. \# 54 d.f. and p.f. except that the seta of $d i$ and $d$ ii are of almost equal length in the latter two species while in the Imicola complex there is a marked difference in lengths. Also, the two species that utilise elephant dung for their larval habitat, i.e. C. loxodontis and C. sp. \# 54 p.f. are the only two species that have the two large protuberances on the operculum. No significant differences were found between the pupae of $C$. sp. \# 54 d.f. reared from the dung of different host species, nor between the pupae of $C$. sp. \# 54 p.f. bred from elephant and white rhinoceros dung.

Where previously the recognition of these two Culicoides species had depended largely on whether they had pale or dark wings, the morphological differences between their pupae leave no doubt that they are indeed two separate species. This is further reinforced by their different larval habitat preferences and other aspects of their biologies.

The present study has again proved the value of comparative pupal morphology as an additional tool towards differentiating between closely related species, and brings to 28 the total number of pupae described for Afrotropical Culicoides.

\section{ACKNOWLEDGEMENTS}

The authors thank the South African National Parks, KwaZulu-Natal Parks and Parks Department of the
Municipality of Tshwane (previously Pretoria) for permission to collect dung; Drs K. Newberry and Karin Kappmeier Green, Messrs R. Meiswinkel and M. Edwardes, and Mrs Marinda Smit for setting time aside to collect dung for this project during field trips; finally, Professor I.G. Horak for his helpful review of the manuscript.

\section{REFERENCES}

DYCE, A.L. \& MARSHALL, B.D. 1989. An early record of Culicoides species (Diptera: Ceratopogonidae) developing in the dung of game animals in southern Africa. Onderstepoort Journal of Veterinary Research, 56:85-86.

MEISWINKEL, R. 1989. Afrotropical Culicoides: a redescription of C. (Avaritia) imicola Kieffer, 1913 (Diptera: Ceratopogonidae) with description of the closely allied $C$. (A.) bolitinos sp. nov. reared from the dung of the African buffalo, blue wildebeest and cattle in South Africa. Onderstepoort Journal of Veterinary Research, 56:23-39.

MEISWINKEL, R. 1995. Afrotropical Culicoides: biosystematics of the Imicola group, subgenus Avaritia (Diptera: Ceratopogonidae), with special reference to the epidemiology of African horse sickness. M.Sc. (Agric.) thesis, University of Pretoria.

MEISWINKEL, R. \& BRAACK, L.E.O. 1994. African horsesickness: five species of Culicoides (Diptera: Ceratopogonidae) collected live behind the ears and at the dung of the African elephant in the Kruger National Park, South Africa. Onderstepoort Journal of Veterinary Research, 61:155-170.

MEISWINKEL, R., VENTER, G.J. \& NEVILL, E.M. 2004. Vectors: Culicoides spp., in Infectious diseases of livestock, edited by J.A.W. Coetzer \& R.C. Tustin, Cape Town: Oxford University Press.

NEVILL, HILDA \& DYCE, A.L. 1994. Afrotropical Culicoides: Description and comparison of the pupae of seven species of the Similis supergroup (Diptera: Ceratopogonidae). Onderstepoort Journal of Veterinary Research, 61:85-106.

NEVILL, HILDA, VENTER, G.J., MEISWINKEL, R. \& NEVILL, E.M. 2007. Comparative descriptions of the pupae of five species of the Culicoides imicola complex (Diptera: Ceratopogonidae) from South Africa. Onderstepoort Journal of Veterinary Research, 74:97-114. 